There are obvious benefits from a high concentration at the required site without systemic ill effects. Though the early trials with dexamethasone showed considerable adrenal suppression at therapeutic doses, ${ }^{1}$ in 1972 beclomethasone was reported as highly successful in controlling bronchial asthma, even allowing withdrawal of oral steroids; and there was no biochemical evidence of adrenal suppression after over a year of treatment. Beclomethasone diproprionate is a synthetic steroid with high anti-inflammatory activity, 5000 times stronger than hydrocortisone. In vivo there is rapid enzymatic degradation to less active beclomethasone monopropionate and inactive beclomethasone. Because it can act on mucous surfaces without much absorption it has been widely used in asthma and eventually in rhinitis. Double-blind crossover trials have shown good relief of nasal symptoms in seasonal, ${ }^{34}$ perennial, ${ }^{5}$ and vasomotor rhinitis, ${ }^{6}$ and nasal polyps. ${ }^{78}$ In most trials symptomatic relief in rhinitis has been confined to nasal obstruction, watery discharge, and sneezing. In children the effects are more pronounced than in adults. Ocular symptoms are not relieved to any great extent. ${ }^{4}$ In all reported trials there have been no important side effects, and we now know that doses of beclomethasone up to $800 \mu \mathrm{g}$ per day do not significantly influence adrenal function. ${ }^{910}$ That its action is local rather than systemic is shown by lack of biochemical changes in the plasma and urine.

A fundamental effect of corticosteroids is that they inhibit protein synthesis. In the nose this might lead to secondary atrophic rhinitis, diffuse bleeding, or reduced resistance to infection. But despite its disadvantages dexamethasone has been used intranasally for over ten years, and side effects of this kind in the upper airways have not been seen. After use of beclomethasone for one year examination with a scanning electron microscope has shown no change in the surface structure of the nasal mucous membrane. ${ }^{8}$ The microbial flora does not alter, ${ }^{6}$ and, though candida pharyngitis has been reported in a small percentage of asthmatics using long-term beclomethasone, this does not seem a problem with nasal use. ${ }^{11}$

What is the optimum dosage ? The standard metered aerosol delivers $50 \mu \mathrm{g}$ of beclomethasone per puff. Two puffs four times a day $(400 \mu \mathrm{g} /$ day $)$ are the optimum in asthma, ${ }^{2}$ and most trials in rhinitis have used a dosage of between 200 and $800 \mathrm{ug}$ day. Nevertheless, the differences in pulmonary and nasal areas suggest that much lower doses might be adequate for nasal use. One trial ${ }^{6}$ indicated no therapeutic difference between 200 and $800 \mu \mathrm{g} /$ day, and the optimum dose may well be below $200 \mu \mathrm{g}$.

A maintenance dose of two puffs twice a day (that is $200 \mu \mathrm{g}$ day) should be adequate for nasal usage, and even this may prove unnecessarily high. Long-term use should be reserved for patients in whom conventional treatment has failed. Even then, it seems reasonable to recommend a precautionary suspension of treatment for one month in every twelve. So today, and with these cautions, beclomethasone may be accepted as a powerful and safe weapon in the symptomatic treatment of allergic and vasomotor rhinitis.

\footnotetext{
${ }^{1}$ Norman, P S, and Winkenwerder, W L, fournal of Allergy, 1965, 36, 284. 2 Brown, H M, Storey, G, and George, W H S, British Medical fournal, $1972,1,585$.

${ }^{3}$ Brown, H M, and Storey, G, British Medical fournal, 1973, 3, 161.

${ }^{4}$ Mygind, N, British Medical fournal, 1973, 4, 464.

5 Gibson, G J, et al, British Medical fournal, 1974, 4, 503.

6 Malm, L, and Wihl, J-A, Acta Allergologica, 1976, 31, 245.

' Mygind, N, et al, Clinical Allergy, 1975, 5, 159.

${ }^{8}$ Mygind, N, et al, Acta Otolaryngologica, 1976, 82, 252.

9 Godfrey, S, and Konig, P, Annals of Allergy, 1974, 33, 150

${ }^{10}$ Harris, D M, et al, Clinical Allergy, 1973, 3, 243.

${ }^{11}$ Milne, L J R, and Crompton, G K, British Medical fournal, 1974, 3, 797.
}

\section{Today's dreams}

Dreams combine a measure of mystery with seeds of fascination. In our times they are little in vogue as a means of foretelling the future, but we may wonder if perhaps Jung was right in thinking that within them can be seen expressions of a primeval heritage, mingling with those features of our individual natures upon which we keep too tight a rein by day. We might even permit ourselves a thought of Freud, and of the hidden passions that our dreams clothe not too indecently. Then what of REM sleep, of which much was heard in the 1960s? Those were the years in which money flowed into laboratory studies of dreams, encouraged by the similarities between dreaming and schizophrenic thought.

Nearly two hours a night are spent in REM (rapid eye movement) sleep, and the finding that awakenings from this sort of sleep could nearly always elicit descriptions of dreams led to the belief that all dreaming occurred at that time and even to the idea that if REM sleep were lacking we should go insane and dream by day. Such notions now are passed away. We have quite typical dreams as soon as we even drowse, ${ }^{1}$ and mental life continues throughout the whole night; we even have night terrors when we are not in REM sleep. ${ }^{2}$ Our thinking during sleep is less easily governed by cold reality, and "primary process" thinking emerges-it is primitive, it is governed by instinct, and discrimination is blurred by emotion. The emotional forces were held by Freud to be half-hidden, allowing the "latent" control of the dream to be glimpsed only through interpretations. The penile erections that form a regular part of REM sleep have lent unexpected support to the idea of cloaked sexuality.

Though mental life continues throughout sleep, primary process thinking is more in evidence during the 20 -minute REM periods, and Molinari and Foulkes ${ }^{3}$ showed that it erupts into the dream in staccato bursts simultaneously with each second or two of rapid eye movements. The pericds of REM sleep recur every 90 minutes, and it is now apparent that there is a parallel rhythm by day that (in a neutral environment) makes thinking become like daydreaming ${ }^{4}$ and oral gratification more likely ${ }^{5}$ every 90 minutes.

The emotional life of the day and of the night have a continuity. Anxious patients are troubled by nightmares, and volunteers who watched a horrifying film of an aboriginal sub-incision rite had anxious dreams with irregular breathing. ${ }^{6}$ Recently Kramer et $a l^{7}$ asked again whether dreams are orderly and not just random and gave to judges the transcripts of dream reports that had been obtained by repeated awakenings out of REM sleep. The judges could sort out the reports and group together not only the dreams of individuals but also, for each individual, the several dreams he had recounted on any single night, confirming that dreams reflect the dayto-day changes in us as well as our enduring individual traits.

It is these traits that are the goal of those who, with Freud, believe that dreams offer a royal road to understanding the mind, provided one can reach beyond its special mode of thinking in the dream. Not least of the problems is the condensation of several themes into one and the recurring play on words (like the transmutation ${ }^{8}$ of Buckingham Palace into the Royal Marsden-the royal ma's den). This assonant wordplay has been studied experimentally ${ }^{9}$ by incorporating external sounds into dreams, so that, for example, the spoken name "Robert" was followed by the description of a dream about a "distorted rabbi."

Dreams are of interest to almost everyone, but whether their study really does lead to a better understanding of a patient's 
personality than can be divined from his waking behaviour is unproved. Their interpretation has certainly influenced modern art, and yet visual dreams are representational, not amorphous or abstract, and are so just as much in art students as in farm boys. ${ }^{10}$ In fact, the vast majority of dreams are not bizarre $^{10}$ but, as a nineteenth century investigator found, are very prosaic and ordinary. ${ }^{11}$

1 Vogel, G, Foulkes, D, and Trosman, H, Archives of General Psychiatry, $1966,14,238$.
${ }^{2}$ British Medical fournal, 1974, 4, 63.

${ }^{3}$ Molinari, S, and Foulkes, D, Perceptual and Motor Skills, 1969, 29, 343.

4 Kripke, D F, in Advances in Sleep Research, vol 1, ed E D Weitzman, p 305. New York, Spectrum Publications, 1974.

5 Oswald, I, Merrington, J, and Lewis, H, Nature, 1970, 225, 959.

6 Goodenough, D R, et al, Psychophysiology, 1975, 12, 313.

7 Kramer, M, et al, American fournal of Psychiatry, 1976, 133, 778.

Faraday, A, Dream Power. London, Hodder and Stoughton, 1972.

- Berger, R J, British fournal of Psychiatry, 1963, 109, 722.

10 Snyder, F, in The Psychodynamic Implications of the Physiological Studies on Dreams, ed L Madow and L H Snow, p 124. Springfield, Charles C Thomas, 1970

11 Calkins. M W, American fournal of Psychology, 1893, 5, 311.

\section{Future of child health services}

Ever since the reorganisation of the NHS in 1974 the medical and nursing staff of former local authority school and infant welfare clinics have been "waiting for Court." As expected, the report of Professor Donald Court's inquiry into child health services ${ }^{1}$ has proposed radical changes: and as feared by the clinic doctors (most of them married women working part-time) they are to become extinct.

The report-vast, detailed, and at times outspoken-opens with a comparison of child health in Britain with that in the rest of Europe. In the last 15-20 years we have slipped down the league table of infant and perinatal mortality, and many of the survivors are handicapped: one child in seven has a handicapping condition of moderate or severe degree sufficient to be a cause of educational concern. The differences in the incidence of first-year deaths and later handicaps between social classes are appalling- "children still die in our lifetimes of nineteenth century reasons," says the report. Disadvantage is not, however, due only to social class: there is a whole new deprived group of 920000 children looked after by a single parent.

While not suggesting that Britain's poor performance has been the fault of the child health services, the report leaves no doubt that these have been fragmented and often inadequate. Treatment of sick children has been divided between general practitioners and the hospitals; prevention and surveillance have been left to the community services; and often contacts between the two have been minimal. Furthermore, says the report, parents should be able to expect "a considerably greater level of paediatric competence among doctors and nurses ... than exists at present."

The solution offered is a unified service in which prevention and treatment are brought together at all levels. This could have been done (as it is in some other European countries) by totally separating paediatrics from adult medicine; but the committee rejected that possibility, largely on the grounds that it would require wasteful and expensive duplication of staff. Instead it proposes that developmental assessment and preventive paediatrics should become the responsibility of general practitioner paediatricians (GPPs). These would all be principals in NHS general practice, with postgraduate experience in paediatrics and special training in developmental medicine. The plan suggests that the average group practice of three to six doctors would have one or two GPPs, so that overall about $40 \%$ of GPs would be paediatricians; their personal lists would include more children than average, but they would by no means abandon adult medicine. From their ranks schools would appoint doctors, and work of that kind would account for about two sessions a week for each GPP.

At the same time the report envisages a substantial expan- sion of the numbers of paediatric specialists in hospitals and in community services for the mentally and physically handicapped and disturbed and in developmental medicine. In each health district (with a total population of 240000 and a child population of 60000 ) it recommends that there should be three consultant paediatricians, one of whom should be committed to the community. This and consequent changes in the training grades would lead to a rise in the number of paediatric consultants (England and Wales) from 393 to 746 , senior registrars from 97 to 182, registrars from 204 to 300, and SHOs from 576 to 812 .

But what about all the staff now working for area authorities ? The report envisages that most clinical medical officers will become GPPs, many of them part-time. Clearly many will lack the formal training requirements and will not want to acquire them, and it suggests a new grade, child health practitioner, for such doctors. In either case, however, the committee expects that the present staff will join one of their local general practices, formally or informally. The rate at which clinical medical officers join group practices as GPPs would, says the report, "be one measure of the success of our proposals and a sensitive indicator of the willingness of child health practitioners to make the approach and of the readiness of general practice to respond." Behind that phrase lies a recognition of the antagonism and mistrust to be found in some parts of the country between doctors in the two branches of the service. In part that distrust has resulted from professional rivalries and genuine or imagined inadequacies in professional competence, but more recently there has been a further factor in the uncertainty about the future of the child health services.

Tragically, that uncertainty will not disappear as a result of publication of this report, whose proposals would, in different circumstances, provide a blueprint for the major reforms that have been needed for so long. For however bold and imaginative the report appears-and of course it was conceived at a time of economic growth-it is now well out of touch with economic realities. Both the expansion in the specialist grades and the assimilation of clinical medical officers to levels of pay that would give them equal status with their new GP partners would be enormously expensive. The danger is that the Government will accept the report in principle and then begin a morale-damaging dismantling of the present structure without the finance or the will to begin building the new one. Our child health services are too important, and the report is too good, for such a fate.

1 Committee on Child Health Services (chairman, Professor S D M Court), Fit for the Future. Volumes 1 and 2, price $£ 10.50$. London, HMSO, 1976. 